\title{
PELATIHAN KEPEMIMPINAN BIDANG KETRAMPILAN PUBLIC SPEAKING, SURVIVAL, CHARACTER BUILDING, DAN COMMUNITY BUILDING BAGI KEBIDELAN SEMINARI ST. PAULUS PALEMBANG
}

\author{
Vausta Nurjanah ${ }^{1^{*}}$, M. K. Fitriani F. ${ }^{2}$, Yohanes Heri Pranoto ${ }^{3}$, \\ Ig. Putra Setiahati ${ }^{4}$, Anselmus Inharjanto ${ }^{5}$ \\ 1,2,3,4,5 Universitas Katolik Musi Charitas, Indonesia \\ ${ }^{1}$ fausta@ukmc.ac.id, ${ }^{2}$ fififruitasari@ukmc.ac.id, ${ }^{3}$ heri_pranoto@ukmc.ac.id, \\ ig_putra@ukmc.ac.id, ${ }^{5}$ anselmus@ukmc.ac.id
}

\begin{abstract}
ABSTRAK
Abstrak: Tujuan dari kegiatan pelatihan kepemimpinan bidang ketrampilan Public Speaking, survival, Character Building, dan Community Buildingbagi kebidelan Seminari Menengah St. Paulus Palembang ini adalah meningkatkan kemampuan kepemimpinan siswa Seminari khususnya pengurus organisasi kesiswaan (kebidelan) dalam Public Speaking, survival, Character Building, dan Community Building. Metode yang dipakai berupa metode mimbar dan praktek dalam kelompok. Kegiatan berlangsung selama 3 hari dengan format camping sehingga ketrampilan survival, Character Building dan Community Building langsung dapat dipraktikkan. Materi dasar manajemen kepemimpinan dan Public Speaking ditempatkan pada hari kedua demi mendukung proses pelatihan dan dilaksanakan secara teoritis dan praktis. Dari hasil kuesioner pelaksanaan kegiatan, didapatkan respon yang positif (56\%) dari seluruh peserta kegiatan menunjukkan signifikansi peningkatan skil peserta dalam kemampuan Public Speaking dan leadership.
\end{abstract}

Kata kunci: Kepemimpinan; Public Speaking; survival; Character and Community Building.

Abstract: The purpose of leadership training activities in the fields of Public Speaking, survival, Character Building, and Community Building skills for Midnight Seminary St. Paulus Palembang is to improve the leadership ability of Seminary students, especially the management of student organizations (kebidelan) in Public Speaking, survival, Character Building, and Community Building. The method used in the form of the pulpit method and practice in groups. The activity lasts for 3 days in a camping format so that survival, Character Building and Community Building skills can be put into practice immediately. The basic materials of leadership management and Public Speaking are placed on the second day to support the training process and are carried out theoretically and practically. From the results of the activity implementation questionnaire, positive responses (56\%) were obtained from all participants shown the significancy skills improve on Public Speaking and leadership.

Keywords: Leadership; Public Speaking; Survival; Character and Community Building.

$\begin{array}{ll} & \text { Article History: } \\ \text { Received: 23-01-2020 } & \text { Revised : 29-02-2020 () } \\ \text { Accepted: 01-03-2020 } \\ \text { Online : 03-03-2020 }\end{array}$




\section{A. LATAR BELAKANG}

Pendidikan bagi para calon Imam harus merupakan perpaduan pengembangan akademik, professional, dengan pendidikan prinsip-prinsip etik, moral, religious dan social (Pilimon, 2000), (Harun, 2015). Semua calon Imam harus diberikan prioritas pada cara-cara yang memungkinkan integrasi pendidikan manusiawi dan professional agar terjadi kesatuan pendidikan intelektual dengan dimensi religious kehidupan (Lande, 2013). Pendidikan yang dimaksud adalah pendidikan formal akademisi disertai dengan pendidikan karakter guna membentuk pribadi-pribadi yang berdaya tahan dan berkemampuan unggul dalam pelayanan di segala bidang (Yunani, 2016).

Seminari Menengah St. Paulus Palembang adalah institusi pendidikan para calon imam dan biarawan di wilayah Keuskupan Agung Palembang. Tingkat pendidikan di Seminari Menengah setara dengan tingkat pendidikan Sekolah Menengah Atas (SMA), dan secara khusus Seminari Menengah St. Paulus bekerja sama dengan SMA Xaverius 1 Palembang dalam proses belajar mengajarnya. Seluruh peserta didik tinggal dalam asrama yang sama dan diberikan pendidikan dengan peraturan yang sama, namun latar belakang masing-masing siswa sering kali menjadi kendala bahkan menghambat perkembangan satu dengan yang lain ketika terjadi benturan budaya, beda pemahaman karena beda level kelas juga kualitas pribadi yang bersangkutan. Tak jarang kondisi nyata ini membuat siswa tak berkembang optimal, sehingga perlu adanya pembinaan dan pendampingan (Soesilo, 2011).

Berdasarkan Buku Pedoman Formatio (2014), Seminari St. Paulus mempunyai visi agar siswa Seminari, atau sering disebut 'seminaris', berkembang secara seimbang dalam 4 S, yakni Sanctitas (kesucian), Sanitas (kesehatan), Scientia (keilmuan), dan Socialitas (kebersamaan), sehingga menjadi pribadi yang dewasa secara manusiawi dan Kristiani dalam mengikuti panggilan Tuhan ke arah imamat atau hidup membiara. Para siswa Seminari Menengah St. Paulus berasal dari berbagai daerah, baik itu di wilayah kerja Keuskupan Agung Palembang, maupun di luar wilayah kerja keuskupan tersebut. Seperti layaknya proses pendidikan di SMA, sebagai penunjang terwujudnya visi tersebut di atas, para seminaris juga dilatih dalam berorganisasi. Terlebih lagi, seminari menggunakan sistem sekolah berasrama (boarding school) sehingga organisasi kesiswaan tidak hanya berlaku saat mereka sekolah formal namun juga ketika mereka tinggal di asrama dan menjalani rutinitas harian. Di sanalah, ketika mereka nyaman dengan keadaan yang ada, mereka niscaya akan bertumbuh dan mengembangkan potensi dan talenta yang ada dalam diri mereka (Christin, 2016).

Dalam konteks latihan berorganisasi tersebut, Seminari St. Paulus mempunyai sistem pembentukan (formatio), dengan didampingi oleh para pembina (formator), yang disebut dengan istilah 'kebidelan'. Sistem kebidelan pada dasarnya serupa dengan OSIS SMA, namun perannya diperluas untuk mengelola hidup berasrama juga. Kepengurusan kebidelan selalu diperbarui per tahun agar para seminaris (juga disebut sebagai formandi) mendapat peran beragam dan mampu bertanggung jawab seturut bidangnya. Pada tahun ajaran 2018-2019, telah terbentuk susunan kebidelan yang baru dan mereka setelah dilantik akan langsung bekerja 
untuk mendukung proses formatio di seminari. Program pelatihan kepemimpinan bidang ketrampilan Public Speaking, survival, Character Building, dan Community Building bagi kebidelan Seminari St. Paulus ditawarkan sebagai pendukung proses formatio tersebut. Fokus dari kegiatan ini adalah memfasilitasi para seminaris yang terpilih dalam kebidelan baru agar nantinya mampu bekerja dalam tim secara efektif dan efisien demi mewujudkan visi seminari. Program yang ditawarkan ini dirangkai dalam konteks kegiatan latihan kepemimpinan (leadership training) yang diselenggarakan oleh Seminari St. Paulus. Secara khusus, program yang kami tawarkan adalah bertujuan untuk membantu para seminaris dalam manajemen kepemimpinan dan diwujudkan dalam pelatihan Public Speaking, survival, Character Building, dan Community Building. Kegiatan ini secara umum diisi dengan materi-materi yang bersifat pengembangan kepribadian dan juga keterampilan (Bustan, 2018). Untuk itu, tim yang memberikan materi terdiri dari dosen yang kompeten dalam bidang tersebut. Public Speaking adalah ketrampilan mendasar bagi seorang pemimpin agar mampu menjalankan tugas yang dipercayakan kepadanya (Swestin \& Primasanti, 2015), (Hakim, 2016). Materi Public Speaking dianggap selalu relevan dalam kegiatan-kegiatan kepemimpinan. Keterampilan ini tidak lekang untuk selalu dikembangkan sebagai indicator kepemimpinan yang efektif (Paramarta \& Sudana, 2016). Seorang pemimpin wajib memiliki keterampilan komunikasi yang baik agar komunitas yang dimpimpinnya dapat berjalan secara efektif dan efisien. Materi yang diberikan tidak hanya "menembak sasaran" pada keterampilan untuk berbicara di depan umum melainkan juga menyampaikan materi dengan jelas, terstruktur, dan masuk akal (logis dan terterima) (Angraini, 2016). Survival adalah bentuk pengembangan ketrampilan ketangguhan untuk bertahan hidup dalam kondisi minim namun tetap mampu mengembangkan talenta (Manusama, 2019). Kemudian, character and Community Building adalah hal mendasar yang semestinya dikuasai oleh seorang pemimpin yang nota bene adalah pelayan dalam sebuah komunitas (Spracklen \& Spracklen, 2015). Berdasarkan kebutuhan tersebut, maka tujuan dilaksanakan kegiatan ini adalah untuk melakukan beberapa hal yakni (1) Penggalian talenta pribadi masing-masing seminaris dalam melaksanakan manajemen diri untuk kepemimpinan, yang sekaligus terkait dengan pengembangan ketrampilan pengembangan karakter dan komunitas (character and Community Building); (2) ketrampilan Public Speaking yang baik sebagai pendukung peran kepemimpinan yang efektif dan efisien; dan (3) ketrampilan survival untuk mengasah ketangguhan peran seorang pemimpin yang sering harus menghadapi situasi sulit dan menantang dalam menjalankan tugas.

\section{B. METODE PELAKSANAAN}

Pelatihan kepemimpinan dilakukan di alam terbuka untuk memberikan kesempatan peserta mengasah daya tahan diri sampai memunculkan kreativitasnya bertahan dalam situasi yang dihadapi. Mitra kegiatan sangat variatif terdiri dari siswa dari semua tingkatan di seminari berjumlah 42 orang peserta yang didampingi oleh guru bidang tata tertib dan kurikulum. 
Dalam kegiatan pelatihan kepemimpinan kebidelan ini diberikan materi kepemimpinan, ketrampilan public speaking, survival, charater building, dan Community Building yang dikemas dengan beberapa dinamika permainan, case study untuk mendapatkan problem solving dari peserta melalui kemampuan berorganisasi dan integritas diri menghadapi kehidupan dengan penuh tanggung jawab. Kepemimpinan adalah materi pembentukan karakter atau character building. Adapun karakter yang dimaksud tidak ditetapkan secara sepihak oleh tim tetapi dengan melihat dinamika dari seluruh peserta. Hal ini untuk membangun self belonging dari seluruh peserta untuk kegiatan ini. Kegiatan ini terintegrasi dengan seluruh materi dan jenis kegiatan. Adapun pencapaian dari peserta dievaluasi setiap sore hari dengan menggunakan system reward dan punishment. Community Building atau membangun komunitas atau kelompok yang sehat adalah materi ketiga dari kegiatan ini. Dalam pelaksanaanya, kegiatan ini dikemas dalam kegiatan dalam kelompok dengan penyampaian materi secara praktis atau bersifat praktik. Kegiatan ini dianggap penting untuk dikemukakan dengan melihat bahwa para seminaris tinggal dan hidup bersama dalam satu komunitas.Pengurus kebidelan yang notabene adalah sebagai pengurus OSIS diharapkan mampu menjadi promotor untuk meningkatkan kualitas hidup berkomunitas. Materi survival adalah materi yang terintegrasi dengan keseluruhan materi pada kegiatan laptim teresebut. Kegiatan dikemas dengan sangat unik dengan mengedankan keterampilan dan pengetahuan peserta untuk bisa bertahan dengan segala kondisi demi tercapainya tujuan atau visi yang telah ditetapkan. Kegiatan ini juga dianggap sebagai fasilitasi atas masalah ketahanan peserta dalam setiap situasi sulit yang mereka hadapi dalam kehidupan mereka. Kegiatan yang diselenggarakan adalah:

1. Menyiapkan materi oleh para pendamping atau narasumber latihan, yaitu tentang berbagai aspek dalam latihan kepemimpinan terutama ketrampilan yang hendak dilaksanakan selama proses, yakni Public Speaking oleh Hery Pranoto, survival oleh Anselmus Inharjanto, Character Building oleh Ignatius Putera, dan Community Building oleh Vausta Nurjanah yang didukung dengan pendidikan kesegaran jasmani dan animasi oleh MK Fruitasari.

2. Menyiapkan lokasi Kebun Sawit di daerah gandus dan kelengkapan sarana prasarana untuk pelatihan karena format yang dipakai adalah camping di kebun sawit. Peserta disediakan tenda untuk setiap kelompok yang harus didirikan sendiri, lalu menyiapkan lokasi MCK masing-masing dan membagikan kebutuhan rumah tangga untuk dikelola oleh masing-masing peserta bersama kelompoknya.

3. Menyiapkan peralatan praktis berupa alat-alat animasi, kebutuhan kebersihan diri (tissue toilet, air galon, obat nyamuk) juga ATK yang dibutuhkan selama kegiatan pelatihan.

4. Menyiapkan angket kuesioner berupa pertanyaan tertutup untuk mengkaji dan mengevaluasi jalannya kegiatan, isi materi dan usulan-usulan peserta terhadap kegiatan pengabdian kepada masyarakat (pelatihan yang diikutinya). Angket menggunakan skala 
Vausta Nurjanah, Pelatihan Kepemimpinan Bidang...

Likert dengan 5 option yakni Sangat Tidak Setuju (STS), Tidak Setuju (TS), Setuju (S), dan Sangat Setuju (SS).

\section{HASIL DAN PEMBAHASAN}

Bentuk evaluasi kegiatan dirangkum dari semua kuisioner yang diisi oleh peserta, kemudian direkap sesuai masing-masing kegiatan dan hasil rekapan dijelaskan berikut ini.

\section{Hasil Pelatihan Character Building}

Hasil kuesioner pada Tabel 1 terlihat pada pernyataan nomor 1 , rata-rata jawaban peserta adalah pada skala 4,31 yang artimya peserta setuju. Pada pernyataan nomor 2, rata-rata jawaban peserta adalah pada skala 4,29. Rata-rata 3,93 adalah untuk pertanyaan nomor 3, yang artinya setuju. Rata-rata paling tinggi terdapat pada nomor 5 dengan skala 4,79 yang artinya sangat setuju dan nomor 6 pada skala 4,57 yang juga berarti sangat setuju. Hasil tersebut dapat dilihat pada Gambar 1 yang memberikan interpretasi yang sangat positif terhadap topik, penyampaian, dan seluruh kegiatan pada Character Building untuk pada pengurus bidel Seminari Santo Paulus Palembang.

Tabel 1. Rekapitulasi Evaluasi Materi Character Building

\begin{tabular}{ccccccccc}
\hline \multirow{2}{*}{ Item } & \multicolumn{2}{c}{ STS } & \multicolumn{2}{c}{ TS } & \multicolumn{2}{c}{ S } & \multicolumn{2}{c}{ SS } \\
\cline { 2 - 9 } & Angka & \% & Angka & \% & Angka & \% & Angka & \% \\
\hline 1 & 0 & 0 & 1 & 2 & 26 & 62 & 15 & 36 \\
\hline 2 & 0 & 0 & 1 & 2 & 27 & 64 & 14 & 33 \\
\hline 3 & 0 & 0 & 5 & 12 & 30 & 71 & 7 & 17 \\
\hline 4 & 0 & 0 & 1 & 2 & 21 & 50 & 20 & 48 \\
\hline 5 & 0 & 0 & 0 & 0 & 9 & 21 & 33 & 79 \\
\hline 6 & 0 & 0 & 1 & 2 & 15 & 36 & 26 & 62 \\
\hline
\end{tabular}

Pertanyaan terbuka terdiri dari beberapa pertanyaan dan bisa direspon dalam satu kali jawaban. Pertanyaan terserbut terkait kesan umum terhadap materi, keinginan untuk diadakannya kembali kegiatan serupa, menarik tidakknya kegiatan, dan topik lain yang bisa diadakan. Dalam rekapitulasi laporan, hasil pertanyaan terbuka ini dibagi menjadi dua, yaitu kesan dan pesan. Berikut pada Tabel 2 adalah rekapitulasi jawaban dari seluruh peserta kegiatan.

Tabel 2. Rekapitualsi Evaluasi Kesan terhadap Materi Character Building

\begin{tabular}{cl}
\hline No. & \multicolumn{1}{c}{ Kesan } \\
\hline 1 & Kegiatan pelatihan ini seru \\
\hline 2 & Kegiatan bermanfaat bagi diri sendiri dan kelompok \\
\hline 3 & Materi yang diberikan mudah dipahami dan tidak ribet. \\
\hline 4 & $\begin{array}{l}\text { Topik dan contoh-contoh yang diberikan elevan dengan kehidupan } \\
\text { saya sehari-hari }\end{array}$ \\
\hline 5 & Kegiatan ini bermanfaat untuk membentuk jati diri \\
\hline 6 & Ada beberapa kegiatan yang membosankan. \\
\hline 7 & Materi jauhari window sangat relevan untuk diri saya sebagai pribadi. \\
\hline 8 & Kegiatan ini menggugah jiwa kepemimpinan saya. \\
\hline 10 & $\begin{array}{l}\text { Kegiatan secara umum menarik karena menggunakan contoh dan } \\
\text { praktik. }\end{array}$ \\
\hline
\end{tabular}


Selain kesan, terdapat pesan juga menjadi poin penting untuk dilihat dari peserta. Adapun hasil pesan dapat dilihat pada Tabel 3 berikut.

Tabel 3. Rekapitualsi evaluasi Pesan terhadap Materi Character Building No.

Pesan

1 Topik serupa bisa dilakukan lagi

2 Topik bisa ditambah dengan wawasan`wawasan

3 Perlu penekanan setiap materi agar mengerti bagian setiap materi.

4 Materi penggunaan bahasa Indonesia yang baik dan benar juga perlu ditambahkan.

Peserta menyampaikan bahwa kegiatan dengan topik yang serupa sangat diharapkan. Selain itu peserta juga berpesan agar materi terkait penggunaan bahasa Indonesia yang baik dan benar perlu untuk ditekankan. Penekanan pada materi juga menjadi penting untuk diperhatikan pada kegaitan berikutnya. Pada Gambar 1 berikut adalah suasana penyampaian materi.

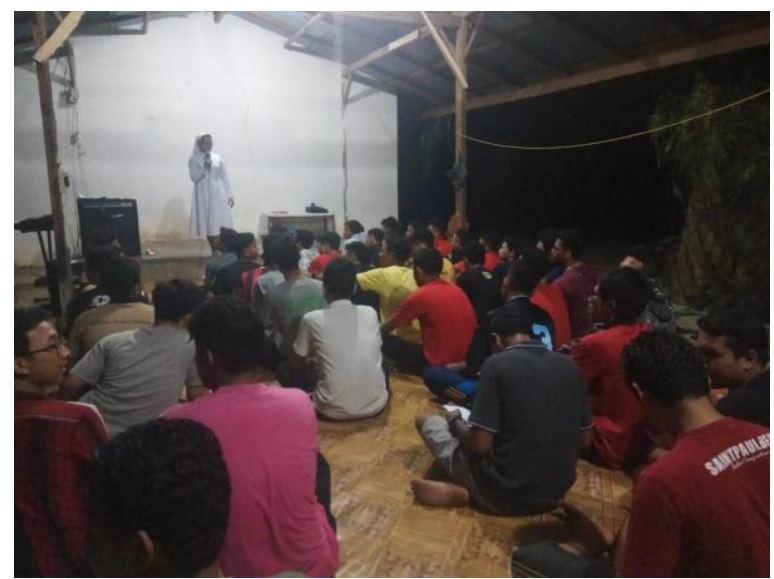

Gambar 1. Kegiatan Penyampaian Materi

\section{Hasil Pelatihan Public Speaking}

Seperti pada materi Character Building, pada Public Speaking juga perlu dilihat akan rata-rata skala dari seluruh respon responden pada setiap butir pertanyaan. Hasil materi pada tahapan ini terlihat pada Tabel 2. Rata-rata tertinggi dengan klasifikasi sangat setuju adalah rata-rata jawaban pada pertanyaan nomor 5, yaitu terkait kebermanfaatan kegiatan, dengan rata-rata skala 4,71. Adapun ratarata terendah dari jawaban peserta ada pada nomor pertanyaan ketiga terkait dengan kejelasan para penyaji dalam menyampaikan materi, yaitu dengan rata-rata skala 4,07. Hasil lengkap terlihat pada Tabel 4 berikut.

Tabel 4. Rekapitulasi Evaluasi terhadap Materi Public Speaking

\begin{tabular}{ccccccccc}
\hline \multirow{2}{*}{ Item } & \multicolumn{2}{c}{ STS } & \multicolumn{2}{c}{ TS } & \multicolumn{2}{c}{ S } & \multicolumn{2}{c}{ SS } \\
\cline { 2 - 9 } & Angka & \% & Angka & $\%$ & Angka & \% & Angka & $\%$ \\
\hline 1 & 0 & 0 & 2 & 5 & 23 & 55 & 17 & 40 \\
\hline 2 & 0 & 0 & 1 & 2 & 22 & 52 & 19 & 45 \\
\hline 3 & 0 & 0 & 5 & 12 & 24 & 57 & 13 & 31 \\
\hline 4 & 0 & 0 & 2 & 5 & 15 & 36 & 25 & 60 \\
\hline 5 & 1 & 2 & 0 & 0 & 7 & 17 & 34 & 81 \\
\hline 6 & 0 & 0 & 2 & 5 & 17 & 40 & 23 & 55 \\
\hline
\end{tabular}


Pada pernyataan nomor 1, rata-rata jawaban peserta setuju dengan skala rata-rata 4,31. Pada pertanyaan kedua, rata-rata skala adalah 4,40 dengan rata-rata jawaban setuju. Pada pertanyaan nomor 4, ratarata skala jawaban adalah 4.50 atau sangat setuju. Dan, jawaban setuju juga ditunjukkan pada rata-rata skala 4,45 pada pertanyaan nomor 6 . Hasil tersebut dapat dilihat pada tabel hasil tersebut memberikan interpretasi yang sangat positif terhadap topik, penyampaian, dan seluruh kegiatan pada Public Speaking untuk pada pengurus bidel Seminari Santo Paulus Palembang.

Seperti pada materi Character Building, pertanyaan terbuka terkait kesan dan pesan juga diberikan kepada seluruh peserta. Berikut pada Tabel 5 adalah rekapitulasi kesan dari seluruh peserta terkait kegiatan dan penyampaian materi kegiatan.

Tabel 5. Rekapitualsi evaluasi Kesan terhadap Materi Public Speaking

\begin{tabular}{cl}
\hline No. & \multicolumn{3}{c}{ Kesan } \\
\hline 1 & Materi ini bermanfaat bagi saya. \\
\hline 2 & $\begin{array}{l}\text { Saya merasa kegiatan ini mampu melatih kepercayaan diri saya } \\
\text { untuk berbicara di depan umum. }\end{array}$ \\
\hline 3 & Materi dikemas dengan jelas dan tidak monoton. \\
\hline 4 & Kegiatan menarik karena banyak praktik. \\
\hline 5 & Saya merasa kegiatan ini cukup menantang. \\
\hline 6 & Materi dapat saya terima dengan baik. \\
\hline 7 & Secara umum menarik, tetapi saya mengalami kendala saat praktik. \\
\hline 9 & Kegiatan baik, tetapi ada beberapa materi yang sulit saya pahami. \\
& $\begin{array}{l}\text { Kegiatan yang paling menarik adalah saat saya harus } \\
\text { mempertahankan argumentasi saya. }\end{array}$ \\
\hline 10 & $\begin{array}{l}\text { Melalui diskusi dan debat, saya belajar untuk mencari solusi dari } \\
\text { masalah. }\end{array}$ \\
\hline 11 & $\begin{array}{l}\text { Kegiatan yang paling mengesan adalah saat kami harus maju ke } \\
\text { depan satu-persatu. }\end{array}$ \\
\hline
\end{tabular}

Dari kesan tersebut dapat disimpulkan bahwa pesrta memiliki kesan positif terhadap kegiatan dan materi yang diberikan pada kegiatan pendampingan Public Speaking untuk pengurus kebidelan Seminari Santo Paulus Tersebut. Selain kesan, pusan juga penting untuk dilihat sesuai Tabel 6 berikut.

Tabel 6. Rekapitualsi Evaluasi Pesan terhadap Materi Public Speaking

\begin{tabular}{cl}
\hline No. & \multicolumn{1}{c}{ Pesan } \\
\hline 1 & Durasi praktik harus diperpanjang. \\
\hline 2 & Kegiatan bisa dikemas dalam kompetisi atau lomba. \\
\hline 3 & Kegiatan bisa dibuat lebih menantang. \\
\hline
\end{tabular}

Ada beberapa hal yang menjadi catatan dari pesan peserta tersebut. Hal pertama yang disampaikan adalah terkait durasi praktik yang disarankan untuk diperpanjang. Hal tersebut memberikan gambaran bahwa durasi waktu yang telah diberikan pada kegiatan tersebut untuk materi public speaking dianggap kurang atau terbatas.

Pesan kedua ditujukan untuk bentuk kegiatan. Peserta memberikan saran agar kegiatan bisa dikemas dalam bentuk lomba atau kompetisi. 
Hal ini juga dirasa baik agar peserta semakin termotivasi untuk berkegiatan.Bentuk kegiatan yang disarankan selanjutnya adalah kegiatan sebisa mungkin menantang. Hal ini sesuai dengan karakter peserta yang homogen, atau laki-laki semua dengan umur yang yang masih muda.

\section{Hasil Pelatihan Communuity Building}

Selanjutnya, untuk melihat keberhasilan dari kegiatan, dianggap perlu untuk melihat rata-rata hasil pernyataan. Rata-rata respon peserta ada pada skala 4 ke atas, yang artinya rentang antar setuju dan sangat setuju dengan setiap item pernyataan. Rata-rata skala tertinggi adalah 4,76 yaitu pada item nomor 5. Sedangkan untuk skala terendah adalah pada item pernyataan nomor 2, yaitu 4,25. Hasil lebih lengkap dapat dilihat pada Tabel 7 berikut.

Tabel 7. Rekapitulasi Evaluasi terhadap Materi Communuity Building

\begin{tabular}{ccccccccc}
\hline \multirow{2}{*}{ Item } & \multicolumn{2}{c}{ STS } & \multicolumn{2}{c}{ TS } & \multicolumn{2}{c}{ S } & \multicolumn{2}{c}{ SS } \\
\cline { 2 - 9 } & Angka & \% & Angka & \% & Angka & \% & Angka & \% \\
\hline 1 & 0 & 0 & 2 & 5 & 21 & 50 & 19 & 45 \\
\hline 2 & 0 & 0 & 1 & 2 & 28 & 67 & 13 & 31 \\
\hline 3 & 0 & 0 & 2 & 5 & 22 & 52 & 18 & 43 \\
\hline 4 & 0 & 0 & 1 & 2 & 18 & 43 & 23 & 55 \\
\hline 5 & 0 & 0 & 0 & 0 & 10 & 24 & 32 & 76 \\
\hline 6 & 0 & 0 & 1 & 2 & 14 & 33 & 27 & 64 \\
\hline
\end{tabular}

Dari hasil tersebut, dapat disimpulkan bahwa materi Community Building bisa diterima oleh seluruh peserta. Sifat kegiatan juga mendapatkan tanggapan yang baik. Hal ini menunjukkan adanya tingkat penerimaan yang sangat positif sehingga harapanya kegiatan teresebut dapat secara berkesinambungkan diadakan kembali.

Seperti halnya pada materi yang lain, inti dari pertanyaan terbuka adalah untuk mendapatkan kesan dan pesan dari seluruh peserta terkait materi Community Building yang telah diberikan. Kesan dan pesan yang diberikan sungguh membantu tim untuk mendapatkan kesan dan pesan secara terbuka dan individual dari seluruh peserta.

Dari kesan yang diberikan, tim mendapatkan penilaian bahwa kegiatan secara umum dikemas secara menarik dan dinilai memberikan manfaat bagi peserta. Ada hal spesifik yang dinilai dari kontribusi materi bagi mereka, yaitu kegiatan ini mampu membangun kebersamaan dan persaudaaraan antar mereka.Selain itu kepekaan dan kepedulian peserta terhadap sesame dan alam sekitar dapat dibangun. Adapun hasilnya sesuai tabel 8 berikut.

Tabel 8. Rekapitualsi Evaluasi Kesan terhadap Materi Community Building

\begin{tabular}{cl}
\hline No. & \multicolumn{1}{c}{ Kesan } \\
\hline 1 & Kegiatan secara umum menarik dan menyenangkan. \\
\hline 2 & Kegiatan ini mampu membangun kebersamaan dan persaudaraan. \\
\hline 3 & $\begin{array}{l}\text { Melalui kegiatan ini, saya mampu lebih peka dan peduli kepada } \\
\text { sesama dan sekitar. }\end{array}$ \\
\hline 4 & Saya mampu membangun kompetensi untuk berkomunikasi. \\
\hline
\end{tabular}




\begin{tabular}{cl}
\hline No. & \multicolumn{1}{c}{ Kesan } \\
\hline 5 & Keakraban dan hidup sosial bisa dibangun dalam kegiatan ini. \\
\hline 6 & $\begin{array}{l}\text { Materi yang diberikan membuka wawasan dan pengetahuan bagi } \\
\text { kami. }\end{array}$ \\
\hline 7 & Kami juga berkembang dalam seni dan kecekatan atau kesigapan. \\
\hline 8 & $\begin{array}{l}\text { Materi yang sangat mengesan adalah saat kami harus } \\
\text { mempertahankan kesolidan kelompok. }\end{array}$ \\
\hline
\end{tabular}

Terkait pesan, dari hasil kuesioner dapat disimpulkan ada tiga pesan utama dari seluruh peserta. Pesan pertama ditujukan untuk bentuk kegiatan. Peserta memberikan pesan agar kegiatan latpim ini dikemas dengan lebih ekstrim dan menantang. Selain itu, focus kegiatan juga bisa ditambah atau ditekankan pada nilai kepedulian. Hal ini bisa diterima dengan baik oleh tim karena mengingat karakter homogenitas peserta yang adalah laki-laki semuanya.

Selain kedua hal tersebut, penyampain materi juga bisa ditambah dengan hal-hal visual. Hal ini memberikan gambaran karakter peserta yang lebih tertarik dengan hal-hal visual. Tim merasakan seluruh pesan memberikan nilai positif demi perkembangan kegiatan yang lebih baik lagi di tahun selanjutnya. Pada Tabel 9 adalah rekapitulasi pesan dari seluruh peserta terhadap materi teresebut.

Tabel 9. Rekapitualsi evaluasi Pesan terhadap Materi Community Building

\begin{tabular}{cl}
\hline No. & \multicolumn{1}{c}{ Pesan } \\
\hline 1 & kegiatan bisa didesain lebih ekstrim lagi. \\
\hline 2 & tema kepedulian lebih diperdalam. \\
\hline 3 & penyampaian materi bisa dalam bentuk visual. \\
\hline
\end{tabular}

Peserta menyampaikan bahwa kegiatan dengan topic yang serupa sangat diharapkan. Selain itu peserta juga berpesan aga materi terkait penggunaan bahasa Indonesia yang baik dan benar perlu untuk ditekankan. Penekanan pada materi juga menjadi penting untuk diperhatikan pada kegaitan berikutnya.

\section{Hasil Pelatihan Survival}

Selanjutnya, untuk melihat hasil kuesioner, rata-rata juga bisa menjadi indikator pencapaian kegiatan. Dilihat dari rata-rata tanggapan peserta didapatkan rata-rata tertinggi adalah pada item nomor 5 dengan tingkat skala 4,79 yang artinya hampir keseluruhan peserta menyatakan sangat setuju bahwa kegiatan survival bermanfaat bagi mereka. Sedangkan nilai rata-rata terendah ada pada item nomor 3 dengan rata-rata ada pada skala 3,93. Lebih detail dapat dilihat pada Tabel 10 berikut.

Tabel 10. Rekapitulasi Evaluasi terhadap Materi Survival

\begin{tabular}{ccccccccc}
\hline \multirow{2}{*}{ Item } & \multicolumn{2}{c}{ STS } & \multicolumn{2}{c}{ TS } & \multicolumn{2}{c}{ S } & \multicolumn{2}{c}{ SS } \\
\cline { 2 - 10 } & Angka & \% & Angka & \% & Angka & \% & Angka & \% \\
\hline 1 & 0 & 0 & 0 & 0 & 23 & 55 & 19 & 45 \\
\hline 2 & 0 & 0 & 1 & 2 & 25 & 60 & 16 & 38 \\
\hline 3 & 0 & 0 & 5 & 12 & 30 & 71 & 7 & 17 \\
\hline
\end{tabular}


52 | JMM (Jurnal Masyarakat Mandiri) | Vol. 4, No. 1, Maret 2020, hal. 43-54

\begin{tabular}{ccccccccc}
\hline \multirow{2}{*}{ Item } & \multicolumn{2}{c}{ STS } & \multicolumn{2}{c}{ TS } & \multicolumn{2}{c}{ S } & \multicolumn{2}{c}{ SS } \\
\cline { 2 - 10 } & Angka & \% & Angka & \% & Angka & $\%$ & Angka & $\%$ \\
\hline 4 & 0 & 0 & 1 & 2 & 12 & 29 & 29 & 69 \\
\hline 5 & 0 & 0 & 0 & 0 & 9 & 21 & 33 & 79 \\
\hline 6 & 0 & 0 & 2 & 5 & 16 & 38 & 24 & 57 \\
\hline
\end{tabular}

Pertanyaan terbuka terdiri dari beberapa pertanyaan dan bisa direspon dalam satu kali jawaban. Terkait dengan kesan dari seluruh peserta, terdapat manfaat secara khusus yang dirasakan oleh peserta. Di antaranya adalah kegiatan teresebut dapat membantu peserta untuk bertanggungjawab, melatih jiwa kepemimpinan, meningkatkan kerjasama tim, meningkatkan kreativitas, melatih untuk hidup di alam, memberi pengetahuan dalam membangun tenda. Sedangkan terkait pesan kegiatan dan penampaian materi, peserta mengungkapkan bahwa kegiatan tersebut menarik, mudah dimengerti dan diterima, serta tidak membosankan. Peserta juga mengharapkan agar kegiatan serupa dapat dilakukan kembali. Keberhasilan kegiatan ini tidak lepas dari management yang baik dari pelaksana, karena management yang baik akan menghasilkan output yang maksimal (Distefano, Rudestam, Silverman, \& Long, 2012), (Farhani, 2019).

\section{SIMPULAN DAN SARAN}

Kegiatan pelatihan kepemimpinan ini adalah untuk menyiapkan peserta menjadi anggota pengurus bidel yang mumpuni dan siap memberikan solusi akan beberapa hal yang belum berjalan efektif di tubuh kebidelan di tahun sebelumnya. Kegiatan ini ada bukan hanya hasil kerja mandiri tim dari UKMC, melainkan juga atas kerjasama yang baik dengan seminari. Karena itulah, keberhasilan kegiatan bukan semata dari tim tetapi juga dari pihak seminari yang telah memfasilitasi kegiatan ini dengan baik.

Materi yang diberikan terkait Public Speaking, survival, Character Building, dan Community Buildingjuga dikemas dengan menarik sesuai dengan karakter peserta yang homogen - semuanya adalah laki-laki pada usia sekolah. Tim yang beranggotakan dari berbagai prodi dan keahlian mencoba untuk mengadaptasi materi-materi yang sesuai dengan keahlian masing-masing dan mengemasnya menjadi satu rangkaian alur materi yang sesuai dengan runtut. Untuk melihat tingkat keberhasilan, satusatunya instrumen yang diadakan adalah kuesioner. Dari hasil pembahasan pada bab sebelumnya disimpulkan bahwa ke-4 materi mendapatkan penilaian yang baik dilihat dari topic, materi, dan proses kegiatan. Pada kuesiner terbuka, dimana peserta bisa mengemukakan kesan dan saran secara bebas, didapatkan kesan dan pesan positif dan dapat diterima demi terwujudkan kegiatan serupa di kesempatan lain.

Ada dua saran berdasarkan PKM ini yang ditujukan bagi pihak seminari dan bagi tim pelaksana PKM, yakni (1) saran bagi pihak Seminari adalah bahwa kegiatan pembekalan yang sudah baik tersebut dapat dipertahankan dan diadakan sebagai kegiatan rutin yang jelas dengan berbagai modifikasi dan perubahan-perubahan yang relevan. Pesan dari peserta juga diharapkan menjadi masukan yang baik sebelum menyusun 
kegiatan serupa di tahun mendatang. Selain komunikasi yang efektif, pengguanaan Bahasa Indonesia yang baik dan benar juga memiliki porsi yang khusus untuk bisa diadakan di kegiatan mendatang. Hal ini bisa juga terintegrasi dengan kegiatan atau materi tulis menulis, seperti pembuatan proposal dan laporan kegiatan. Peserta juga memberikan saran terhadap kegiatan ini, yaitu: agar dilanjutkan bagi kepengurusan kebidelan di tahun selanjutnya dengan penambahan materi-materi yang relevan, seperti penggunaan Bahasa Indonesia yang baik dan benar; dan (2) Saran bagi Tim PKM yaitu: agar tim bisa melibatkan disiplin ilmu yang lain, seperti Psikologi agar kegiatan semakin mengkerucut pada pengenalan jati diri dari kualitas diri demi pembangunan komunitas kebidelan yang lebih matang dan terukur.

\section{UCAPAN TERIMA KASIH}

Terima kasih diucapkan kepada semua pihak yang telah ikut berpartisipasi dalam kegiatan PKM ini, terutama terimakasih kepada LPPM Unika Musi Charitas Palembang atas segala bantuannya yang memperlancar proses perijinan pelaksanaan PKM ini, terima kasih kepada kampus tercinta FIKES Unika Musi Charitas atas kesempatan yang diberikan untuk ikut berpartisipasi dalam PKM ini, terima kasih kepada Seminari Santo Paulus Palembang sebagai mitra pelaksanaan PKM juga terimakasih kepada para Dosen dan Mahasiswa panitia kegiatan PKM, semua kerjasama dan kebersamaan kita sangat mengesan.

\section{DAFTAR RUJUKAN}

Angraini, Y. (2016). Rules of Three Analysis in Persuasive Public Speaking Presentation. ANGLO-SAXON: Jurnal Ilmiah Program Studi Pendidikan Bahasa Inggris, 7(1), 3. https://doi.org/10.33373/anglo.v7i1.542

Bustan, R., \& Fitria, N. (2018). Pelatihan Kiat Membangun Karakter Anak. Jurnal Al-Azhar Indonesia Seri Humaniora, 4(1), 25. https://doi.org/10.36722/sh.v4i1.250

Christin, M., Primadani, B., Putri, S., \& Putra, R. A. (2016). Pengaruh Kualitas Pelayanan Asrama Telkom University Terhadap Kepuasan Mahasiswa Penghuni Asrama Angkatan 2015/2016. E-Proceeding of Management, 3(3), 3677-3684.

Distefano, A., Rudestam, K., Silverman, R., \& Long, P. D. (2012). Learning Management Systems (LMS). In Encyclopedia of Distributed Learning. https://doi.org/10.4135/9781412950596.n99

Farhani, D. (2019). Manajemen Pendidikan Karakter Melalui Kegiatan Kokurikuler Keagamaan. Jurnal Isema: Islamic Educational Management, 4(2), 209-220. https://doi.org/10.15575/isema.v4i2.5619

Hakim, M. A. R. (2016). Pengembangan Materi Bahan Ajar Public Speaking Berbasis Communicative Language Teaching Bagi Mahasiswa di Indonesia. Manhaj, 04(3), 230-238. https://doi.org/10.1017/CBO9781107415324.004

Harun, M. (2015). Yohanes Bambang Mulyono, Sejarah dan Penafsiran Leksionaris Versi RCL, Jakarta: Grafika KreasIndo, https://doi.org/10.26551/diskursus.v14i2.53

Lande, A. E. (2013). Menjalin Sinergi Antara Sekolah Teologi Dengan Gereja Dalam Mengupayakan Gerakan Misi. Jurnal Antusias, 2(4).

Manusama, L. (2019). Allah dan Alam. KENOSIS: Jurnal Kajian Teologi, 1(2), 187-203. https://doi.org/10.37196/kenosis.v1i2.28

Paramarta, I. M. S., \& Sudana, P. A. P. (2016). Perbandingan Komunikasi 
54 | JMM (Jurnal Masyarakat Mandiri) | Vol. 4, No. 1, Maret 2020, hal. 43-54

Nonverbal Penutur Asli Dan Penutur Asing Bahasa Inggris Dalam Public Speaking. Jurnal Ilmu Sosial Dan Humaniora, 5(1). https://doi.org/10.23887/jish-undiksha.v5i1.8287

Pilimon, J. E. (2000). Hubungan Sekolah Teologi, Rohaniwan Lulusannya dan Gereja. Veritas: Jurnal Teologi Dan Pelayanan, 1(1), 53-67. https://doi.org/10.36421/veritas.v1i1.27

Soesilo, Y. (2011). Gereja dan Pluralisme Agama dalam Konteks di Indonesia. Jurnal Antusias, 1(2), 81-93.

Spracklen, K., \& Spracklen, K. (2015). Character and Community Building. In Exploring Sports and Society (pp. 54-69). https://doi.org/10.1007/978-1-13734160-0_5

Swestin, G., \& Primasanti, K. B. (2015). Public Speaking Dalam Konteks Pengajaran. Scriptura, 4(2). https://doi.org/10.9744/scriptura.4.2.60-68

Yunani, A. (2016). Gereja Santo Antonius Purbayan: Sejarah Awal Gereja Katolik Belanda di Solo. Jurnal Lektur Keagamaan, 14(1), 229. https://doi.org/10.31291/jlk.v14i1.482 